\title{
No.45
}

\section{DICIEMBRE DE 2019}

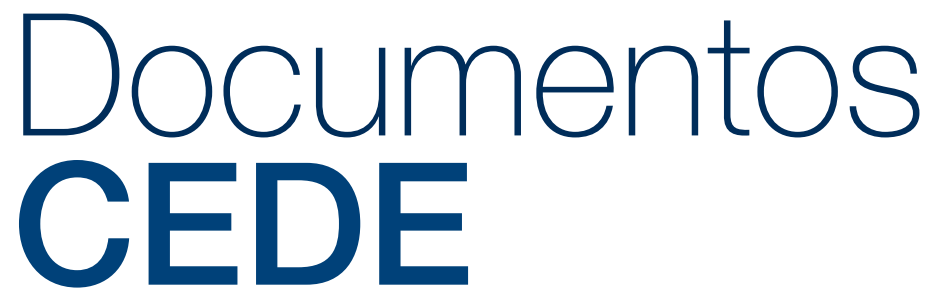

ISSN 1657-7191 Edición electrónica.

Bequests, Imperfections in Factor Markets, and Long-Run Inequality: A Theoretical Assessment of Piketty

Andrés Álvarez

Camilo Gómez

Hernando Zuleta 


\section{CEDE}

D1)

Facultad de Economía

Serie Documentos Cede, 2019-45

ISSN 1657-7191 Edición electrónica.

Actualizado en Enero de 2020

(C) 2019, Universidad de los Andes, Facultad de Economía, CEDE. Calle 19A No. 1 - 37 Este, Bloque W.

Bogotá, D. C., Colombia Teléfonos: 3394949- 3394999, extensiones 2400, 2049, 2467

infocede@uniandes.edu.co

http://economia.uniandes.edu.co

Impreso en Colombia - Printed in Colombia

La serie de Documentos de Trabajo CEDE se circula con propósitos de discusión y divulgación. Los artículos no han sido evaluados por pares ni sujetos a ningún tipo de evaluación formal por parte del equipo de trabajo del CEDE.

El contenido de la presente publicación se encuentra protegido por las normas internacionales y nacionales vigentes sobre propiedad intelectual, por tanto su utilización, reproducción, comunicación pública, transformación, distribución, alquiler, préstamo público e importación, total o parcial, en todo o en parte, en formato impreso, digital o en cualquier formato conocido o por conocer, se encuentran prohibidos, y sólo serán lícitos en la medida en que se cuente con la autorización previa y expresa por escrito del autor o titular. Las limitaciones y excepciones al Derecho de Autor, sólo serán aplicables en la medida en que se den dentro de los denominados Usos Honrados (Fair use), estén previa y expresamente establecidas, no causen un grave e injustificado perjuicio a los intereses legítimos del autor o titular, y no atenten contra la normal explotación de la obra.

Universidad de los Andes | Vigilada Mineducación

Reconocimiento como Universidad: Decreto 1297 del 30 de mayo de 1964. Reconocimiento personería jurídica: Resolución 28 del 23 de febrero de 1949 Minjusticia. 


\section{Bequests, Imperfections in Factor Markets, and Long-Run Inequality: A Theoretical Assessment of Piketty|*}

\author{
Andrés Álvareq
}

\author{
Camilo Gómez|
}

\author{
Hernando Zuleta $\beta^{\beta}$
}

JEL classification: D31, D33, O41

Keywords: Inequality, growth, bequests, factor shares, Piketty.

*We thank participants at the CEDE Seminar-Universidad de los Andes and SEA 88th annual Meetings. We are also grateful to David Pérez and Tomás Rodríguez, for their helpful suggestions on previous versions of this paper, and María Medellín, Lukas Delgado, and Laura Gómez, for their discussions on the preliminary ideas at the origin of this project.

${ }^{\dagger}$ Department of Economics, Universidad de los Andes, Bogotá, Colombia. E-mail: ca.alvarez967@uniandes.edu.co.

'Banco de la República and Department of Economics, Universidad de los Andes, Bogotá, Colombia. E-mail: ac.gomez10@uniandes.edu.co.

$\S$ Department of Economics, Universidad de los Andes, Bogotá, Colombia. E-mail: h.zuleta@uniandes.edu.co. 


\title{
Herencias, imperfecciones en el mercado de factores y desigualdad de largo plazo: una evaluación teórica de Piketty
}

\author{
Andrés Álvarez Camilo Gómez Hernando Zuleta
}

\begin{abstract}
Con la publicación del libro El capital en el siglo XXI de Thomas Piketty (2014), se ha renovado el debate político y académico sobre la desigualdad del ingreso y la riqueza. Las críticas teóricas a las ideas de Piketty se han centrado principalmente en la regularidad expuesta por el autor sobre el hecho de que la tasa de crecimiento de la economía es menor que la tasa de interés, mientras que han dejado escapar dos aspectos relevantes para entender la dinámica de la desigualdad: las herencias y la divergencia entre los precios de los factores y sus productividades marginales. Este artículo presenta un modelo de generaciones traslapadas que incorpora estos elementos y estudia bajo que circunstancias un equilibrio de desigualdad entre dos grupos sociales (dinastías pobres y ricas) es posible en el largo plazo con crecimiento positivo. El modelo considera dos bienes, uno esencial y el otro no esencial. Se encuentra que la desigualdad entre pobres y ricos es posible cuando (i) el producto marginal del trabajo en el sector que produce el bien esencial esta acotado por arriba y la productividad marginal del capital en el sector que produce el bien no esencial está acotada por abajo por un número positivo; y (ii) las remuneraciones a los factores no son determinadas por las fuerzas convencionales de la productividad marginal.
\end{abstract}

Clasificación JEL: D31, D33, O41

Palabras clave: Desigualdad, crecimiento, herencias, participación de los factores, Piketty. 


\section{Introduction}

The book Capital in the Twenty-First Century by Thomas Piketty (2014) has renewed the public and scholar debate about wealth and income inequality. The stylized facts underlined by Piketty indicate that there is a recent increase in the concentration of wealth in modern market and industrialized economies. Furthermore, this work seems to point out the possibility of a natural, persistently increasing inequality in the long term in the absence of re-distributional government actions.

Piketty suggests the existence of an inequality trap: given an original unequal distribution, richer families tend to accumulate wealth faster than the poorer ones. Among other insights, the author points out what he considers a main regularity behind the dynamics of long-term inequality, that is, as long as the growth rate of product $g$ is lower than the interest rate $r$, the inequality of wealth increases. The above is the famous $r>g$.

Consequently, attention has concentrated mostly on this theoretical conjecture and several authors have criticized it 1 In particular, Mankiw (2015), and Krusell and Smith 2015) develop a critical point of view on this conjecture in a neoclassical growth model framework with only one good and infinitely-lasting agents who do not leave bequests. As usual in a textbook model of this type, the inequality $r>g$ is a natural equilibrium result and does not tell anything about the possibility of an inequality trap.$^{2}$

These interpretations of Piketty's message, however, have overlooked the importance of two central elements behind his conjecture. First, the crucial role of bequests and inter-generational accumulation of wealth (Piketty, 2014, p. 379-380, 390-393). Second, the increasing returns of financial capital investments characterizing modern economic regimes (Piketty, 2014, Chapter 6).

In this paper, we propose a theoretical assessment of Piketty that incorporates these two elements. More specifically, we build an overlapping generation (OLG) model that investigates the possibility of some agents not leaving bequests and Piketty's insight about the fact that factor remunerations are not determined by marginal productivity through competitive factor markets.

Most previous theoretical critiques of Piketty are unfair since they suppose infinitelyliving agents and only one sector economy, making impossible to make sense of the

\footnotetext{
${ }^{1}$ Others have focused their attacks on Piketty's methods for collecting his data. For instance, see Potter (2014).

${ }^{2}$ Indeed, this natural result in a standard theoretical model is recognized by Piketty (2014, p. 360) himself.
} 
way familiar dynasties accumulate along generations. Besides, the common theoretical framework also supposes that factor remunerations are determined by marginal productivity, ignoring Piketty's insistence on a non-standard definition of factor returns. Even if he does not go as far as to propose a full conceptual treatment of the problem, it is clear enough that he considers an original point of view about the return on capital and labor and their dynamics.$^{3}$ In several passages of the book, Piketty (2014, p. 212, 359-361) indicates that factor remunerations are not determined by the standard economic forces, i.e., the marginal productivity of capital and labor, and the discount rate. The role of imperfect competition or, at least, of non-competitive market forces on the determination of the distribution of income between capital and labor earnings is crucial to understand Piketty's conclusions. This is the main ground on which the author aims at explaining the reasons behind $r>g$.

Our model considers an economy with two sectors, one producing an essential consumption good and the other a non-essential good. The economy is populated by rational agents belonging to an infinitely-lasting dynasty. We do not suppose any differences in preferences, discount rates, or any subjective behavior between agents or dynasties. $4^{4}$ Our main assumption about the differences between agents relates to their initial wealth and income restrictions, and the existence of a threshold allowing agents to have enough capacity to leave bequests and consume the non-essential good. We propose a general form of preferences implying that once the agent gets to consume enough of the essential good, she can leave bequests and consume the non-essential good. Therefore, similar to the convexities in the bequest function introduced by Moav (2002), agents with initially high levels of income save for the prosperity of the dynasty, whereas those with initially low levels of income save solely for retirement since they only can consume the essential good.

If capital and labor are not highly substitutable in the essential sector, and the opposite is the case in the sector producing capital and the non-essential good, production in the former is constrained, while the marginal product of capital in the latter is bounded by a positive value. Consequently, it is possible the persistence of inequality across two different types of dynasties, one rich and the other poor, in a growing economy. The rich one saves in order to perpetuate the fortune of the family, and the poor

\footnotetext{
${ }^{3}$ In this sense, Mihalyi and Szelényi (2017) point out what they consider some inconsistencies in Piketty's definitions of wealth and capital. They underline the necessity to differentiate several forms of capital and wealth instead of following a standard definition of these variables.

${ }^{4}$ For instance, Mankiw (2015) and Mattauch et al. (2018) suppose that workers and capitalists have different preferences. The later also assume different discount rates between economic classes.
} 
dynasty does not leave any form of inheritance since their initial income is not enough.

One interesting Pikettyan feature of the model is that a differential treatment of the technologies between both sectors and a non-competitive determination of the factorial distribution of income are crucial for sustaining a scenario with persistent inequality across dynasties in the long run. We prove that, even with the elasticities mentioned, if factor remunerations are determined by the standard economic forces of the marginal product, then the coexistence of rich and poor dynasties is not equilibrium compatible in the long run with economic growth. The elasticities making feasible long-run growth of capital and the existence of poor agents imply that the production technology of the essential good converges asymptotically to a BL function. Therefore, the supply of the essential good is tied to the real wage. In this vein, production must be low for the existence of poor agents, as their earnings depend on the wage income in the essential sector. In this case, however, the supply of the essential good is so low that rich agents are not able to consume the subsistence level of this good. In consequence, an inequality equilibrium with the persistence of rich and poor could not prevail.

The impossibility result about the persistence of inequality raises a distributional conflict for the persistence of the two social groups. Thus, in the last part of the paper, we explore a more Pikettyan distributional setting in factor markets. We study an economic environment where one exogenous rule defines the labor income share in the sector producing the essential good. Following Piketty (2014, p. 212), we interpret this exogenous rule as a result of the bargaining power of workers and capitalists. We demonstrate that (i) for the long-run existence of the poor dynasty, it is necessary that the labor income share be sufficiently low; and (ii) for the coexistence of both rich and poor agents, it is necessary that the long-run production in the essential sector be high enough to satisfy the aggregate demand of both type of agents.

When analyzing this non-competitive environment in factor markets, we employ two tractable Constant Elasticity of Substitution (CES) production functions in order to provide comparative statics about the effects of changes in factorial distribution and bequest motives on long-term inequality. Due to the complexity of the long-run solution of the model, we solve it numerically. We draw four main conclusions from these exercises. First, for a general range of parameters, inequality of wealth is higher than inequality of income. Second, both income and wealth distribution are skewed in favor of rich dynasties. Indeed, under different combinations of parameter levels, more than $90 \%$ of wealth and income are on the hands of rich agents. Third, the higher the income distributed to labor and the lesser the intensity of the bequest leaning, 
the lower the level of both income and wealth inequalities. Fourth, even if income inequality remains constant, its persistence is accompanied by increasing inequality of consumption.

In contrast with the previous literature aiming at giving a theoretical rationale to Piketty's empirical evidence, we emphasize bequest motives behind saving decisions and study alternative distributional environments in factor markets, considering imperfections.5 Moreover, unlike Ederer and Rehm (2018), and Mattauch et al. (2018), who suppose that workers and capitalist have different preferences and discount rates, we analyze how it is possible that from the same type of preferences can arise two types of agents, namely, dynasties that save for the fortune of the family and those that save for retirement. We also consider how the existence of these types of agents depends on differentiated characteristics of the productive sectors and the distributional environments in factor markets within a general equilibrium framework. This contrasts with the partial equilibrium analysis in Jones (2015) ${ }^{6}$

This paper is also connected to the literature on structural transformation. This literature offers two explanations for the positive trend in the share of services and the negative trend in the share of agriculture: the demand side, which relies on nonhomothetic preferences (Kongsamut et al., 2001; Foellmi and Zweimüller, 2002; Buera and Kaboski, 2012; Matsuyama, 2002), and the supply side, which relies on biased sectorial growth (Buera et al., 2013, 2015; Kane, 1919).7] According to the demanddriven theory of structural change, as households become richer, the demand for certain goods grow so does output in these sectors.

The model we present can be understood as a demand-driven structural change model since the relative demand for the non-essential good grows as per-capita income grows. Nevertheless, our emphasis is on the possibility of persistent or increasing inequality in a context of economic growth and wage growth. In other words, our question is: Can a demand-driven model of structural transformation generate growth and

\footnotetext{
${ }^{5}$ We are aware that, beyond the debate on how to make theoretical sense of Piketty's analysis, there is a large strand of macroeconomic literature studying inequality in the context of stochastic shocks, frictions, and biased innovations. For an extensive literature review, see Quadrini and Rios-Rull (2015).

6 Jones (2015) considers $r>g$ in a context of a Pareto distribution of wealth and analyzes how the wedge between the interest rate and the growth rate can increase inequality of wealth in partial equilibrium. He shows that higher $r-g$ is related to higher wealth inequality when $r$ and $g$ are exogenous. This results does not hold when general equilibrium effects are considered.

${ }^{7}$ Authors like Krüger (2008), Acemoglu and Guerrieri (2008), Herrendorf et al. (2014) make reference to the importance of inequality and its effects on structural change.
} 
persistent inequality in the long run?

The remaining of this paper is organized as follows. Section 2 presents the model and rationalizes our concept of an inequality equilibrium. Section 3 analyzes the main longrun results for general production functions and a competitive environment in factor markets. Section 4 explores under which circumstances we can produce a long-term inequality equilibrium when factor remunerations in the essential sector are determined by an exogenous distributional rule. Section 5 briefly concludes.

\section{Model Configuration}

In this section, we introduce the basic setting of our OLG model. First, we present the consumer's problem. In our framework, the agent consumes when young and old, and leaves bequests while old. We consider two kinds of goods: one essential and the other non-essential. The preferences of the agent are lexicographic in the sense that she must consume at least a necessary level of the essential good to demand the other good and leave bequests.

We then introduce the types of agents deriving from the consumer's preferences. Rich agents are those who receive wealth from their predecessors and thus have high enough initial endowments to consume the non-essential good and leave bequests. By contrast, poor agents do not receive wealth from their parents and only save for their retirement.

Finally, we introduce the general production functions operating in each economic sector and the equilibrium conditions for markets. As we shall see in Section 3, the elasticities of substitution in each sector are crucial for sustaining positive growth of capital and the persistence of inequality between rich and poor dynasties.

\subsection{Consumption}

Consider a dynasty of two period-lived agents who consume goods $x$ and $y$, and leave bequests $b$ to their descendants. In this way, the agent utility depends on the consumption when young $c x$ and $c y$, when old $d x$ and $d y$, and on the inter-generational transfer $b$. In our setting, good $y$ is non-essential and good $x$ is essential in the sense that there exists a necessary level of consumption $\mu>0$. Once the agent consumes $\mu$ of good $x$, she derives utility from the consumption of good $y$ and from the bequest $b$. For young people, income is given by the wage $w$ plus the transfer received from parents 
$b$. Defining the gross interest rate as $r$ and assuming that old people are the owners of firms, for old people income is given by the returns to savings $s, r s$, and profits $\Pi$. We employ good $y$ as a numeraire and define $p$ as the relative price of good $x$. Finally, we assume zero population growth and, for tractability, a logarithmic utility function.

The problem reads as follows

$$
\max _{\left\{c x_{t}, d x_{t}, c y_{t}, d y_{t+1}, b_{t+1}, s_{t}\right\}} U= \begin{cases}\log c x_{t}+\log c y_{t}+\beta\left[\log d x_{t+1}+\right. & \\ \left.\log d y_{t+1}+\gamma \log b_{t+1}\right], & \text { if } c x_{t} \geq \mu \\ \log c x_{t}+\beta \log d x_{t+1}, & \text { if } c x_{t}<\mu\end{cases}
$$

subject to

$$
w_{t}+b_{t}=p_{t} c x_{t}+c y_{t}+s_{t}
$$

and

$$
r_{t+1} s_{t}+\Pi_{t+1}=p_{t+1} d x_{t+1}+d y_{t+1}+b_{t+1}
$$

Now we turn to the tree possible solutions of the consumer's problem and characterize them in terms of the initial endowments. At first, we study the solution when the agent can consume more than the threshold $\mu$. Then, we analyze the case in which the consumer chooses $c x<\mu$. Finally, we study when she consumes just this necessary level of good $x$ and derives utility from the consumption of good $y$ and the bequests.

\subsubsection{Interior solution with $c x_{t}>\mu$}

This is the case where the consumer has enough resources to demand more than $\mu$ of good $x$. Therefore, she also derives utility from the consumption of the non-essential good. Let $Z$ be the inter-temporal endowment of the consumer. Specifically, $Z_{t}$ is equal to wage income $w_{t}$ plus the inheritance $b_{t}$ and the present value of future profits $\Pi_{t+1} / r_{t+1}$ :

$$
Z_{t}=w_{t}+b_{t}+\frac{\Pi_{t+1}}{r_{t+1}}
$$


As shown in appendix A, in this case the consumer's demands are:

$$
\begin{aligned}
c x_{t} & =\frac{1}{2+\beta(2+\gamma)} \frac{Z_{t}}{p_{t}}, \\
c y_{t} & =\frac{1}{2+\beta(2+\gamma)} Z_{t}, \\
d x_{t+1} & =\frac{\beta r_{t+1}}{2+\beta(2+\gamma)} \frac{Z_{t}}{p_{t}} \frac{p_{t}}{p_{t+1}}, \\
d y_{t+1} & =\frac{\beta r_{t+1}}{2+\beta(2+\gamma)} Z_{t+1},
\end{aligned}
$$

and

$$
b_{t+1}=\frac{\gamma}{2+\gamma}\left(r_{t+1} s_{t}+\Pi_{t+1}\right)=\frac{\gamma \beta r_{t+1}}{2+\beta(2+\gamma)} Z_{t} .
$$

From expression (4), it follows that if

$$
\frac{Z_{t}}{p_{t}}>\mu(2+\beta(2+\gamma))
$$

then this interior solution is feasible. In other words, the agent consumes the nonessential good and leaves bequests as long as her endowment is high enough to consume the quantity $\mu$ of good $x$.

\subsubsection{Interior solution with $c x_{t}<\mu$}

In this scenario the initial endowment of the agent does not allow her to consume more than the necessary consumption $\mu$ of good $x$. Thus, she does not derive utility from the consumption of the non-essential good and the bequests and chooses $c y_{t}, d y_{t+1}, b_{t+1}=0$.

As we develop in Appendix A, in this case the solutions are:

$$
\begin{aligned}
c x_{t} & =\frac{1}{1+\beta} \frac{Z_{t}}{p_{t}}, \\
c y_{t} & =0 \\
d x_{t+1} & =\frac{\beta}{1+\beta} r_{t+1} \frac{Z_{t}}{p_{t}} \frac{p_{t}}{p_{t+1}} . \\
d y_{t+1} & =0
\end{aligned}
$$


and

$$
b_{t+1}=0
$$

Equation (9) implies that one necessary condition for this solution is

$$
\frac{Z_{t}}{p_{t}}<\mu(1+\beta)
$$

Therefore, the initial endowment of the agent in terms of the essential has to be constrained. As we will discuss in the next case of the consumer's problem solution, for the long-run existence of this solution, a more restrictive condition on $Z_{t} / p_{t}$ is needed when prices are growing.

\subsubsection{Corner Solution with $c x_{t}=\mu$}

From Sections 2.1.1 and 2.1.1 we know critical income levels below which the agent only consumes good $x$ and above which the agent consumes $x$ and $y$, and leaves a positive bequest $b$. There is, however, a gray zone. If $\mu(2+\beta(2+\gamma)) \geq Z_{t} / p_{t} \geq \mu(1+\beta)$, then the agent is not rich enough to consume good $y$ and leave bequest according to the solution of Section 2.1.1, but she is sufficiently rich to have a consumption level of $x$ above $\mu$. In this case, we suppose that the agent consumes a quantity $\mu$ of good $x$ and allocates the rest of her income to the other good and to leave an inheritance, intended to maximize utility.

The consumer with this initial income decides consumption levels and bequests according to the following equations (see Appendix $\mathrm{A}$ for the complete derivation):

$$
\begin{aligned}
c x_{t} & =\mu, \\
c y_{t} & =\frac{1}{1+\beta(2+\gamma)}\left(Z_{t}-p_{t} \mu\right), \\
d x_{t+1} & =\frac{\beta r_{t+1}}{1+\beta(2+\gamma)}\left(\frac{Z_{t}}{p_{t+1}}-\frac{p_{t}}{p_{t+1}} \mu\right), \\
d y_{t+1} & =\frac{\beta r_{t+1}}{1+\beta(2+\gamma)}\left(Z_{t}-p_{t} \mu\right),
\end{aligned}
$$


and

$$
b_{t+1}=\frac{\gamma}{2+\gamma}\left(r_{t+1} s_{t}+\Pi_{t+1}\right)=\frac{\gamma \beta r_{t+1}}{1+\beta(2+\gamma)}\left(Z_{t}-p_{t} \mu\right)
$$

From the above expressions, notice that for any income level such that

$$
\frac{Z_{t}}{p_{t}}>\mu
$$

this solution is feasible. Therefore, comparing solutions of Sections 2.1.2 and 2.1.3. if the initial endowment $Z_{t} / p_{t}$ is higher than $\mu$ and the relative price of good $x$ is growing, then there would be incentives for demanding the non-essential good and leaving inheritance instead of choosing $c x<\mu$. Thus an inequality trap is not possible, as argued by Lemma 1 .

Lemma 1. If $\left(p_{t}\right)_{t=1}^{\infty}$ is increasing and $\mu<Z_{t} / p_{t}<\mu(1+\beta)$, then there exists $t^{*}$ such that the agent chooses $c x_{t^{*}}=\mu, c y_{t^{*}}, d y_{t^{*}+1}, b_{t^{*}+1}>0$.

Proof. The utility $U_{t}^{1}$ related to the interior solution with $c x_{t}<\mu$ is:

$$
U_{t}^{1}=\log \left(\frac{1}{1+\beta} \frac{Z_{t}}{p_{t}}\right)+\beta \log \left(\frac{\beta}{1+\beta} r_{t+1} \frac{Z_{t}}{p_{t}}\right) .
$$

On the other hand, the utility $U_{t}^{2}$ associated with the corner solution of Section 2.1.3 is:

$$
\begin{aligned}
U_{t}^{2}=\log \mu+\log ( & \left.\frac{p_{t}}{1+\beta(2+\gamma)}\left(\frac{Z_{t}}{p_{t}}-\mu\right)\right)+\beta\left[\log \left(\frac{\beta r_{t+1}}{1+\beta(2+\gamma)} \frac{p_{t}}{p_{t+1}}\left(\frac{Z_{t}}{p_{t}}-\mu\right)\right)+\right. \\
& \left.\log \left(\frac{\beta r_{t+1} p_{t}}{1+\beta(2+\gamma)}\left(\frac{Z_{t}}{p_{t}}-\mu\right)\right)+\gamma \log \left(\frac{\gamma \beta r_{t+1} p_{t}}{1+\beta(2+\gamma)}\left(\frac{Z_{t}}{p_{t}}-\mu\right)\right)\right] .
\end{aligned}
$$

As $Z_{t} / p_{t}$ is bounded, $U_{t}^{1}$ is bounded as well. Besides, if the sequence of the relative price of good $x$ is increasing, then $U_{t}^{2} \longrightarrow \infty$ as $t$ grows. Therefore, there is some $t^{*}$ such that $U_{t^{*}}^{2}>U_{t^{*}}^{1}$ and the consumer chooses $c x_{t^{*}}=\mu, c y_{t^{*}}, d y_{t^{*}+1}, b_{t^{*}+1}>0$.

In our theoretical framework, we suppose that the agent initiates to demand good $y$ and the bequests once she has reached a level $\mu$ of consumption of good $x$ only when young. If we define the poor dynasty as the one choosing $c x_{t}, d x_{t+1}<\mu$, a 
weaker condition on $Z_{t} / p_{t}$ is needed 8 Nonetheless, in a model of this type the main qualitative results derived hold. One possible interpretation for the definition of poor people depicted below is that the poor dynasty can sacrifice the consumption of the essential good when old in favor of leaving bequests for the prosperity of the young members of the dynasty.

\subsection{Types of Agents: Rich and Poor Dynasties}

Having studied the possible solutions for the consumer's problem depending on the initial endowment in Section 2.1, in this Section we define the types of agents that we analyze in the economic equilibrium of the model. In this paper, we investigate an economy with two kinds of dynasties: rich and poor. The former can choose $c x_{t}>\mu$, and the latter is consumption-constrained so that they only can get $c x_{t}<\mu 9^{9}$

\subsubsection{Rich dynasty}

Rich are those who have enough income allowing them to consume more than the necessary level $\mu$ of the essential good. We denote their endowments and optimal levels of consumption and savings with the superscript $R$. These agents receive bequests $b_{t}^{R}$ from their predecessors and are also the owners of firms. Therefore, their initial endowment $Z_{t}^{R}$ satisfies the following equation

$$
\frac{Z_{t}^{R}}{p_{t}}=\frac{w_{t}+b_{t}^{R}}{p_{t}}+\frac{\Pi_{t+1}}{p_{t} r_{t+1}}>\mu(2+\beta(2+\gamma))
$$

and they choose consumption and bequests according to equations (4)-(8).

Equation (21) states that the income of the rich dynasty depends on (i) wages; (ii) the initial capital of the dynasty, since the bequests depend on the savings of the aging generation (equation 8); (iii) parents' profits (see again equation 8); and (iv) the present value of future profits.

\footnotetext{
${ }^{8}$ In this case, the inequality deriving from the solution explored in Section 2.1 .2 is $Z_{t} / p_{t}<\mu(1+$ $\beta) \min \left\{1, \frac{p_{t+1}}{p_{t} r_{t+1} \beta}\right\}$, and the condition of Lemma 1 is $Z_{t} / p_{t}<\mu\left(1+\frac{p_{t+1}}{p_{t} r_{t+1}}\right)$.

${ }^{9}$ Note that we are not characterizing the corner solution with $c x_{t}=\mu$ presented in Section 2.1.3. Without loss of generality, this allows us to get a simple and sharp characterization of differences between dynasties.
} 
From (4), (5), and (2a), it follows that the savings of the rich dynasty $s_{t}^{R}$ are:

$$
s_{t}^{R}=\frac{1}{2+\beta(2+\gamma)}\left[\left(w_{t}+b_{t}^{R}\right) \beta(2+\gamma)-2 \frac{\Pi_{t+1}}{r_{t+1}}\right] .
$$

\subsubsection{Poor dynasty}

Following the same logic used to define rich agents, poor are those who are consumption constrained by their income level. For these agents, income is not enough to consume the threshold level $\mu$ of the essential good. Therefore, they cannot leave bequests and, consequently, save for the life cycle and not for the prosperity of the dynasty. We denote the solutions of the poor dynasty with the superscript $P$.

The poor dynasty does not receive inheritance at $t$, and its profits are zero since firms are owned by rich dynasties. Thus, for poor people the initial endowment $Z_{t}^{P}$ in terms of good $x$ is:

$$
\frac{Z_{t}^{P}}{p_{t}}=\frac{w_{t}}{p_{t}}
$$

Hence, according to Lemma 1, if

$$
\frac{w_{t}}{p_{t}} \leq \mu
$$

this type of agent decides consumption demands based on expressions (9)-12 and chooses $b_{t+1}^{P}=0$.

The existence of the poor dynasty in a growing economy with increasing prices requires the wage income measured in units of the essential good to be low. Since the poor dynasty does not possess capital, its income solely depends on the wage paid while young, in contrast to the initial endowments received by the wealthy dynasty (see equation 21).

Equations $(9)$ and 10 imply that the saving function of the poor dynasty $s_{t}^{P}$ is given by a fraction of wage earnings:

$$
s_{t}^{P}=\frac{\beta}{1+\beta} w_{t} .
$$

Therefore, comparing formulas 22 and (25), the differences in saving behavior across dynasties have their roots not in subjective preferences for time (parameter $\beta$ ) but in the initial wealth and income of agents. This is consistent with the claim of Piketty (2014, p. 390-393) regarding saving patterns. The author emphasises that one of the main motives behind accumulation relates to the desire of perpetuate the fortune of 
the family. In our model, the above crystallizes in the sense that some agents with high initial levels of wealth and income continue perpetuating the fortune of the dynasty, whereas individuals with low initial wealth and income only save for their old age.

\subsection{Production}

On the production side, we suppose that sector $Y$ produces capital and consumption goods. Sector $X$, in contrast, produces only the essential good. The aggregate quantities of goods $x$ and $y, X$ and $Y$, are produced with two factors of production, capital $K$ and labor $L$. Let us define the labor hired by sector $X$ and $Y$ as $L_{X}$ and $L_{Y}$, respectively. Similarly, let $K_{X}$ and $K_{Y}$ be the capital used in each sector. Production occurs according to the two following functions $F: \mathbb{R}_{+}^{2} \rightarrow \mathbb{R}_{+}$and $G: \mathbb{R}_{+}^{2} \rightarrow \mathbb{R}_{+}$,

$$
\begin{aligned}
Y_{t} & =F\left(K_{Y_{t}}, L_{Y_{t}}\right), \\
X_{t} & =G\left(K_{X_{t}}, L_{X_{t}}\right) .
\end{aligned}
$$

We assume that $F$ and $G$ exhibit constant returns to scale and diminishing marginal products. We do not impose, however, the Inada conditions, as this would depend on the asymptotic properties of the elasticity of substitution. As we detail in Section 3 , these elasticities are key for sustaining positive economic growth and the coexistence of the two kinds of dynasties in the long run.

Assumption 1. $F$ and $G$ are homogenous of degree 1, twice continously differentiable, and

$$
\begin{aligned}
F_{K_{Y}}(\cdot), G_{K_{X}}(\cdot), F_{L_{Y}}(\cdot), G_{L_{X}}(\cdot) & >0 \\
F_{K_{Y} K_{Y}}(\cdot), G_{K_{X} K_{X}}(\cdot), F_{L_{Y} L_{Y}}(\cdot), G_{L_{X} L_{X}}(\cdot) & <0 .
\end{aligned}
$$

\subsection{Equilibrium}

For the analysis of the persistence of inequality in the long-run equilibrium with economic growth, we see under which circumstances can prevail both dynasties when the economy is growing at a constant positive rate. Therefore, we do not study the origins of inequality and its dynamics. Instead, we analyze how an initial distribution of population could sustain. As we do not consider population growth, total labor $L$ is normalized to one. Let $\eta, 1-\eta \in(0,1)$ be the initial fraction of rich and poor peo- 
ple, respectively. The following definition rationalizes the study of an equilibrium with persistence of inequality across types of agents.

Definition (Inequality Equilibrium). In this model, an Inequality Equilibrium is a sequence of prices $\left\{p_{t}, r_{t}, w_{t}\right\}_{t=1}^{\infty}$, factor allocations $\left\{K_{X_{t}}, K_{Y_{t}}, L_{X_{t}}, L_{Y_{t}}\right\}_{t=0}^{\infty}$, and consumers' decisions $\left\{c x_{t}^{j}, d x_{t+1}^{j}, c y_{t}^{j}, d y_{t+1}^{j}, b_{t+1}^{j}, s_{t}^{j}\right\}_{t=1}^{\infty}, j=R, P$, such that:

(i) $\left\{K_{X_{t}}, K_{Y_{t}}, L_{X_{t}}, L_{Y_{t}}\right\}_{t=0}^{\infty}$ solve the problem of the firms given $\left\{p_{t}, r_{t}, w_{t}\right\}_{t=1}^{\infty}$;

(ii) consumers' decisions $\left\{c x_{t}^{j}, d x_{t+1}^{j}, c y_{t}^{j}, d y_{t+1}^{j}, b_{t+1}^{j}, s_{t}^{j}\right\}_{t=1}^{\infty}$ solve the consumer's problem for all cohorts given $\left\{p_{t}, r_{t}, w_{t}\right\}_{t=1}^{\infty}$;

(iii) given the total supply of labor $L_{t}=1$ and $\eta$, the sequence of prices guarantees that all markets clear and that the fraction $(1-\eta)$ of the population continues being poor.

From the previous definition, notice that for the existence of an inequality equilibrium, we must ensure that the economy can produce, at least, the minimum demand of good $x$ of the rich dynasty.

Assumption 2. In order to sustain the rich dynasty, we suppose that, for all $t$,

$$
G\left(K_{X_{t}}, L_{X_{t}}\right)>\eta \mu
$$

In what follows we present the different market clearing conditions of the model.

Capital Market. For simplicity we suppose full depreciation of capital. Thus, total capital supplied in $t, K_{t}$, is given by the total savings of the preceding generations $S_{t-1}$, which is a weighted average of the savings of the two dynasties and is allocated in the two productive sectors $X$ and $Y$ :

$$
\begin{aligned}
S_{t-1} & =\eta s_{t-1}^{R}+(1-\eta) s_{t-1}^{P} \\
& =K_{t}=K_{X_{t}}+K_{Y_{t}}
\end{aligned}
$$

There is capital mobility. Demands of capital depend on the distributional structure in factor markets analyzed in Sections 3 and 4 .

Labor Market. In equilibrium total labor supply $L_{t}=1$ is distributed between the two sectors:

$$
1=L_{Y_{t}}+L_{X_{t}}
$$


We also suppose labor mobility across sectors. As in the case of the capital market, labor demands vary depending on the distributional structure assumed in factor markets.

Market of goods. Capital and bequests accumulate in sector $Y$. Then, in equilibrium,

$$
Y_{t}=F\left(K_{Y_{t}}, L_{Y_{t}}\right)=S_{t}+B_{t}+C Y_{t}+D Y_{t}
$$

where the capital letters are the aggregate demands of consumers. Given that the fraction of rich people is equal to $\eta$, the last expression becomes

$$
Y_{t}=F\left(K_{Y_{t}}, L_{Y_{t}}\right)=\eta\left(s_{t}^{R}+c y_{t}^{R}+b_{t}^{R}+d y_{t}^{R}\right)+(1-\eta) s_{t}^{P}
$$

On the other hand, in sector $X$,

$$
\begin{aligned}
X_{t} & =G\left(K_{X_{t}}, L_{X_{t}}\right)=C X_{t}+D X_{t} \\
& =\eta\left(c x_{t}^{R}+d x_{t}^{R}\right)+(1-\eta)\left(c x_{t}^{P}+d x_{t}^{P}\right) .
\end{aligned}
$$

\section{Main Long-Run Results for General Production Functions and a Competitive Environment}

This Section presents the main results of the model for general production functions and a competitive environment in factor markets. We focus our analysis on the possibility of a long-run inequality equilibrium with constant positive growth. More specifically, we see that under the elasticities of substitution making possible constant positive growth and the existence of poor agents, if factor remunerations are determined by the standard economic forces of marginal products, the coexistence of rich and poor dynasties is not equilibrium compatible.

We start by defining constant positive growth as the case where (i) all markets clear; and (ii) capital in both sectors grows at constant positive rates. The constant growth rate of capital in sector $Y, g_{K}>0$, is given by

$$
\frac{K_{Y_{t+1}}}{K_{Y_{t}}}=1+g_{K} .
$$


With perfect competition in factor markets, firms maximize profits in each sector:

$$
\begin{array}{r}
\max _{\left\{K_{Y_{t}}, L_{Y_{t}}\right\}} \Pi_{t}^{Y}=F\left(K_{Y_{t}}, L_{Y}\right)-w_{t} L_{Y_{t}}-r_{t} K_{Y_{t}}, \\
\max _{\left\{K_{X_{t}}, L_{X_{t}}\right\}} \Pi_{t}^{X}=p_{t} G\left(K_{X_{t}}, L_{X_{t}}\right)-w_{t} L_{X_{t}}-r_{t} K_{X_{t}} .
\end{array}
$$

Therefore, the first-order conditions imply

$$
\begin{aligned}
w_{t} & =F_{L_{Y}}\left(K_{Y_{t}}, L_{Y_{t}}\right)=p_{t} G_{L_{X}}\left(K_{X_{t}}, L_{X_{t}}\right), \\
r_{t} & =F_{K_{Y}}\left(K_{Y_{t}}, L_{Y_{t}}\right)=p_{t} G_{K_{X}}\left(K_{X_{t}}, L_{X_{t}}\right),
\end{aligned}
$$

and profits received by rich dynasties $\Pi_{t}=\Pi_{t}^{Y}+\Pi_{t}^{X}$ are set to zero.

Define $k_{Y}$ and $k_{X}$ as per-worker capital, and $f\left(k_{X}\right)$ and $g\left(k_{Y}\right)$ as per-worker production in sectors $X$ and $Y$, respectively. By the implicit function theorem, expressions (36a) and (36b) imply that

$$
\frac{\partial k_{X_{t}}}{\partial k_{Y_{t}}}>0
$$

i.e., if there is economic growth in sector $Y$, then capital in sector $X$ also grows.

Let $\sigma_{X}\left(k_{Y}\right)$ and $\sigma_{Y}\left(k_{X}\right)$ be the elasticities of substitution in each sector:

$$
\begin{aligned}
& \sigma_{X}\left(k_{X}\right)=-\frac{g^{\prime}\left(k_{X}\right)\left(g\left(k_{X}\right)-k_{X} g^{\prime}\left(k_{X}\right)\right)}{k_{X} g\left(k_{X}\right) g^{\prime \prime}\left(k_{X}\right)}, \\
& \sigma_{Y}\left(k_{Y}\right)=-\frac{f^{\prime}\left(k_{Y}\right)\left(f\left(k_{Y}\right)-k_{Y} f^{\prime}\left(k_{Y}\right)\right)}{k_{Y} f\left(k_{Y}\right) f^{\prime \prime}\left(k_{Y}\right)} .
\end{aligned}
$$

If $\sigma_{Y}(\infty)$ is well defined and higher than 1 , technology converges to $A K$ in sector $Y$, and perpetual growth of capital is achievable since the marginal productivity of capital converges to a positive value. Moreover, if there is constant positive growth, it follows that $r>g$. Proposition 1 formalizes this result.

Proposition 1. If $\sigma_{Y}(\infty)>1, \frac{K_{Y_{t}}}{K_{Y_{t+1}}} r_{t} \geq 1$ is a necessary condition for constant positive growth.

Proof. Suppose that there is constant positive growth. A well-known result (see Barelli and de Abreu, 2003) is that if $\sigma_{Y}(\infty)>1$, then

(i) $f^{\prime}(\infty)>0$; and

(ii) $\lim _{K_{Y} \rightarrow \infty} \frac{K_{Y} F_{K}(\cdot)}{F(\cdot)}=1$. 
Therefore, $F$ converges to $A K_{Y}$ when capital is growing, where $A>0$ is the asymptotic marginal product of capital in sector $Y$.

This implies that, in the long run, $\frac{Y_{t}}{K_{Y_{t}}}=A$. Then,

$$
\frac{K_{Y_{t+1}}}{K_{Y_{t}}}=\frac{K_{Y_{t+1}}}{Y_{t}} A
$$

Since sector $Y$ accumulates capital, $0<\frac{K_{Y_{t+1}}}{Y_{t}} \leq 1$. In this way,

$$
\frac{K_{Y_{t}}}{K_{Y_{t+1}}} A=\frac{K_{Y_{t}}}{K_{Y_{t+1}}} r_{t} \geq 1
$$

The last result shows that the $r>g$ inequality is indeed a natural equilibrium outcome in a model of economic growth. In fact, $r<g$ would imply that the economy would be in a dynamically-inefficient scenario since capital would be over-accumulated. Piketty recognizes this. However, he also offers more interesting insights regarding what he is referring about $r>g$. In particular, Piketty (2014, p. 212, 359-361) argues that factor returns do not follow the traditional forces of marginal product, a case we study in Section 4.

Recall that, for the existence of the poor dynasty, production in sector $X$ is required to be bounded in such a way that wage earnings in units of good $x$ are constrained. Sufficient for this in a growing economy is that production in sector $X$ converges to a $B L$ technology, which is granted if capital and labor are complements, i.e., if $\sigma_{X}(\infty)<1$. Proposition 2 demonstrates this result.

Proposition 2. If $\sigma_{X}(\infty)<1$, then the poor dynasty can sustain in the long-run with constant positive growth of capital.

Proof. Suppose that there is constant positive growth of capital. Barelli and de Abreu (2003) prove that if $\sigma_{X}(\infty)<1$, then

(i) $\lim _{K_{X} \rightarrow \infty} G(\cdot)<\infty$; and

(ii) $\lim _{K_{X} \rightarrow \infty} \frac{L_{X} G_{L_{X}}(\cdot)}{G(\cdot)}=1$.

Then, production in sector $X$ converges to a linear function of $L_{X}$, that is,

$$
X_{t}=B L_{X_{t}}
$$


where $B>0$ is the asymptotic marginal product of labor in sector $X$. Therefore, equation 40 implies that $w_{t} / p_{t}$ is bounded and given by $B$.

The last result indicates that if capital and labor are complements in sector $X$, the poor dynasty might exist in the long run. With an elasticity of substitution above or equal to 1 , wage earnings would allow the poor dynasty to leave bequests to their descendants. In particular, if $\sigma_{X}\left(k_{X}\right)=1$, production technology in sector $X$ occurs according to a Cobb-Douglas function and, with economic growth, labor income in this sector would also grow. As well, if $\sigma_{X}\left(k_{X}\right)$ were constant and greater than 1 , the marginal product of labor would increase if capital is expanding.

In what follows we only consider the case where growth is positive and production in the essential sector is bounded. Then, we suppose that $\sigma_{X}(\infty)<1$ and $\sigma_{Y}(\infty)>1$. This assumption has three relevant implications with respect to the market equilibrium. First, given that technology in sector $X$ transforms into $B L_{X}, w_{t} / p_{t}$ becomes constant. Second, from equations (22) and 25), capital in sector $Y$ grows at the same rate as prices. Third, in the long-run equilibrium with constant positive growth, $L_{X_{t}}=1$ because $w_{t} / p_{t}$ and $Y_{t} / p_{t}$ are constants, and in sector $Y$ the wage income share is equal to zero 10

Now we turn to the main result of this paper. From Proposition 1, the marginal productivity of capital in sector $Y$ converges to a positive value, allowing for the possibility of positive growth. On the other hand, Proposition 2 points out that if capital and labor are complements in sector $X$, wage in terms of the essential good is bounded, and the poor dynasty may continue being poor in the long term. Nevertheless, given the production function of good $x$, the supply of good $x$ is tied to the real wage. This implies that both dynasties could not coexist. If the poor dynasty prevails, the real wage must be low $\left(w_{t} / p_{t} \leq \mu\right)$, but the supply of good $x$ is so small in this case that rich agents cannot consume the subsistence level of the essential good. Therefore, it is not possible an inequality equilibrium combined with economic growth. Proposition 3 formally presents the previous argument.

Proposition 3. If there is constant positive growth, then an inequality equilibrium cannot exist in the long run.

\footnotetext{
${ }^{10}$ To see this note that

$$
\frac{w_{t} L_{Y_{t}}}{Y_{t}}=\frac{w_{t} / p_{t} L_{Y_{t}}}{Y_{t} / p_{t}}=0
$$
}

in the long run, so $L_{Y_{t}}=0$. 
Proof. Looking for a contradiction, let us suppose that there exists an inequality equilibrium with constant positive growth. With constant positive growth, $w_{t} / p_{t}$ and $b_{t}^{R} / p_{t}$ are constants, and $L_{X}=1$. Then, the long-run equilibrium in good $x$ market implies:

$$
B=\frac{\eta}{2+\beta(2+\gamma)}\left(\frac{w_{t}+b_{t}}{p_{t}}\right)\left(1+\beta A \frac{p_{t-1}}{p_{t}}\right)+\frac{1-\eta}{1+\beta} \frac{w_{t}}{p_{t}}\left(1+\beta A \frac{p_{t-1}}{p_{t}}\right) .
$$

From Proposition 1: $A \frac{p_{t-1}}{p_{t}} \geq 1$. Therefore,

$$
B \geq \frac{\eta}{2+\beta(2+\gamma)}\left(\frac{w_{t}+b_{t}}{p_{t}}\right)(1+\beta)+(1-\eta) \frac{w_{t}}{p_{t}}
$$

The existence of the rich dynasty requires: $\frac{w_{t}+b_{t}}{p_{t}}>\mu(2+\beta(2+\gamma))$. Then,

$$
B>\eta \mu(1+\beta)+(1-\eta) \frac{w_{t}}{p_{t}}
$$

Given perfect competition, in the long run $B=w_{t} / p_{t}$. Hence,

$$
w_{t} / p_{t}>(1+\beta) \mu
$$

which contradicts the conditions under which a poor dynasty is equilibrium compatible, i.e., $w_{t} / p_{t} \leq \mu$. Then, if factor remunerations are determined by marginal productivities, rich and poor cannot coexist in the long run.

In our framework, inequality is defined as a situation where there is no convergence, in the long term, of savings behavior between two dynasties starting with different levels of wealth. In a nutshell, Proposition 3 indicates that long-run savings for the rich and poor dynasties differ because of the behavior of factor markets. In fact, this model becomes a standard two-sectorial OLG model where $s_{t}^{R}-s_{t}^{P}$ converges to zero when factor markets are competitive, and factor remunerations obey to the marginal productivity law (see Zuleta 2015). In this scenario, agents become homogeneous in the long-run with economic growth, and an inequality equilibrium does not exist.

The main message of Proposition 3 and the above discussion takes us back to Piketty. A natural distributional conflict between rich and poor emerges when the conditions of the above definition of inequality prevail: a part of the workers' productivity in sector $X$ is distributed to capital, a case we analyze in the next Section. 


\section{Main Long-Run Results for CES Production Func- tions and a Non-Competitive Environment}

In this Section we explore under which circumstances an inequality equilibrium is feasible, and we provide some comparative statics of the long-run inequality of wealth and income. We show that the crucial turn to obtain such a result is to consider a non-competitive scenario in sector $X$ in which an exogenous distributional rule governs factor remunerations. This setting has important implications on the behavior of sector $X$ related to the dynamics of capital accumulation, factor remunerations, and the level of production.

To carry out this exploration, we consider the case where $F$ and $G$ are two CES production functions, which only differ in their elasticities of substitution $\sigma_{Y}$ and $\sigma_{X}$, respectively:

$$
Y_{t}=F\left(K_{Y_{t}}, L_{Y_{t}}\right)=\left[\left(A K_{Y_{t}}\right)^{\frac{\sigma_{Y}-1}{\sigma_{Y}}}+\left(B L_{Y_{t}}\right)^{\frac{\sigma_{Y}-1}{\sigma_{Y}}}\right]^{\frac{\sigma_{Y}}{\sigma_{Y}-1}}
$$

and

$$
X_{t}=G\left(K_{X_{t}}, L_{X_{t}}\right)=\left[\left(A K_{X_{t}}\right)^{\frac{\sigma_{X}-1}{\sigma_{X}}}+\left(B L_{X_{t}}\right)^{\frac{\sigma_{X}-1}{\sigma_{X}}}\right]^{\frac{\sigma_{X}}{\sigma_{X}-1}}
$$

where $\sigma_{X}<1<\sigma_{Y}$. This assumption ensures that poor and rich dynasties can coexist in a scenario of perpetual growth. This also goes in line with the insights of Piketty (2014, p. 220-221) about the possibility of an elasticity of substitution higher than 1 , given the alternative uses of capital and the process of innovation in the economy.

We consider imperfections in the labor market. This assumption derives directly from Proposition 3. In particular, we study a setting where wage income in sector $X$ is given by the expression

$$
\frac{w_{t}}{p_{t}}=\phi \frac{X_{t}}{L_{X_{t}}}
$$

where $\phi \in(0,1){ }^{11}$ Following Piketty (2014, p. 212), we interpret $\phi$ as a parameter depending on the bargaining power of workers and capitalists. Higher values of $\phi$

\footnotetext{
${ }^{11}$ This assumption is isomorphic to a model where there is imperfect competition in both sectors. The advantage of analysing imperfections only in one sector is that it simplifies our computational exercises. If the non-competitive scenario is present in both sectors, the main qualitative results hold, since there is perfect mobility of labor and capital.
} 
imply that workers have more power in the setting on wages, while lower $\phi$ means that capitalists present more economic and political control when wages are fixed.

Given the exogenous distributional rule, the optimization problem for firms in sector $X$ becomes

$$
\max _{\left\{K_{X_{t}}\right\}} \Pi_{t}^{X}=(1-\phi) p_{t}\left[\left(A K_{X_{t}}\right)^{\frac{\sigma_{X}-1}{\sigma_{X}}}+\left(B L_{X_{t}}\right)^{\frac{\sigma_{X}-1}{\sigma_{X}}}\right]^{\frac{\sigma_{X}}{\sigma_{X}-1}}-r_{t} K_{X_{t}}
$$

whereas firms in sector $Y$ follow the same problem presented in equation (34). Therefore, the first-order conditions imply the following determinants of factor remunerations:

$$
\begin{aligned}
& w_{t}=F_{L_{Y}}\left(K_{Y_{t}}, L_{Y_{t}}\right)=p_{t} \phi \frac{G\left(K_{X_{t}}, L_{X_{t}}\right)}{L_{X_{t}}}, \\
& r_{t}=F_{K_{Y}}\left(K_{Y_{t}}, L_{Y_{t}}\right)=(1-\phi) p_{t} G_{K_{X}}\left(K_{X_{t}}, L_{X_{t}}\right) .
\end{aligned}
$$

The above expressions have three relevant implications. First, if there is positive economic growth, then $L_{X}$ converges to one. Second, as shown in Appendix B, profits in sector $X$ are

$$
\frac{\Pi_{t}^{X}}{p_{t}}=(1-\phi) G_{L_{X}}\left(K_{X_{t}}, L_{X_{t}}\right) L_{X_{t}}
$$

while $\Pi_{t}^{Y}=0$ for all $t$. And third, from equations $(46 \mathrm{~b})$ and $(47)$, it follows that total capital income in sector $X$ is given by:

$$
\frac{r_{t} K_{X_{t}}+\Pi_{t}^{X}}{p_{t}}=(1-\phi) X_{t}
$$

According to equations (47) and (48), capital receives the part of product which is not distributed to labor. We can decompose capital income into two elements. The first is due to profits and is proportional to the bargaining power of capitalists $(1-\phi)$ and to the labor income that workers would earn in a scenario with perfect competition $G_{L_{X}}\left(K_{X_{t}}, L_{X_{t}}\right) L_{X_{t}}$. The second corresponds to the capital market returns $r_{t} K_{X_{t}} / p_{t}$.

The way the factor incomes are allocated between rich and poor agents has dynamic distributional consequences. Profits are received by rich dynasties when old and are partially transferred to their heirs through bequests. On the other hand, since poor people do not own firms and obtain nothing of inheritance, they only receive capital income when old through their savings in the capital market. However, this capital income in the production of the essential good becomes irrelevant in the long run, as 
demonstrated by Proposition 4.

Proposition 4. In the long-run equilibrium with constant positive growth, if distribution is given by the exogenous rule $\phi$ of equations (44), then

$$
\frac{K_{X_{t+1}}}{K_{X_{t}}}<\frac{K_{Y_{t+1}}}{K_{Y_{t}}}=\frac{p_{t+1}}{p_{t}}
$$

and

$$
\frac{r_{t} K_{X_{t}}}{p_{t}}=0
$$

Proof. Suppose an economy with factor remunerations given by the exogenous distributional rule $\phi$ of expression (44) and constant positive growth. From equation (47), it follows that the long-run value of profits in terms of good $x$ is

$$
\frac{\Pi_{t}^{X}}{p_{t}}=(1-\phi) B,
$$

since technology in sector $X$ converges to a $B L$ production function, and $L_{X_{t}}=1$.

Equations (48) and (46) imply that the long-run value of capital income in sector $X$ is

$$
A \frac{K_{X_{t}}}{p_{t}}+(1-\phi) B=(1-\phi) B
$$

Hence,

$$
r_{t} K_{X_{t}} / p_{t}=0
$$

Further, since capital grows at a rate equal to the growth rate of price, and capital is accumulated in sector $Y$,

$$
\frac{K_{X_{t+1}}}{K_{X_{t}}}<\frac{K_{Y_{t+1}}}{K_{Y_{t}}}=\frac{p_{t+1}}{p_{t}}
$$

Proposition 4 points out that this is a model of imbalanced growth: capital in sector $X$ grows at a lower rate than aggregate capital. Further, the growth rate of prices and capital in sector $Y$ equalize, while the production in sector $X$ stagnates. In this scenario, good $x$ becomes more expensive so that the poor dynasty has to devote more and more resources to consume the same amount of $x$.

The feasibility of an inequality equilibrium have two significant consequences in 
factor income distribution and production. On one hand, for the poor to exist in the long-term equilibrium, wage in units of the essential good is required to be low. This is granted for low values of the labor income share $\phi$ as Proposition 5 shows.

Proposition 5. In the long-run equilibrium with constant positive growth, if distribution is given by the exogenous rule $\phi$ of equation (44), a necessary condition for the existence of the poor dynasty is

$$
\phi \leq \frac{\mu}{B}
$$

Proof. Follows directly from Lemma $1{ }^{12}$

On the other hand, in this economic environment the long-run equilibrium in good $x$ market is given by:

$$
B=\frac{\eta}{2+\beta(2+\gamma)}\left(\frac{w_{t}+b_{t}}{p_{t}}+\frac{\Pi_{t+1}}{p_{t} r_{t+1}}\right)\left(1+\beta A \frac{p_{t-1}}{p_{t}}\right)+\frac{1-\eta}{1+\beta} \frac{w_{t}}{p_{t}}\left(1+\beta A \frac{p_{t-1}}{p_{t}}\right),
$$

where $\Pi_{t}=\Pi_{t}^{X}$. Therefore, for the existence of both dynasties, production has to be high enough to satisfy the demand of rich and poor agents, as Proposition 6 argues.

Proposition 6. In the long-run equilibrium with constant positive growth, if distribution is given by the exogenous rule $\phi$ of equation (44), the inequality

$$
B>\frac{\eta \mu(1+\beta)}{1-(1-\eta) \phi}
$$

is necessary for the existence of the rich and poor dynasties. Besides, sufficient for (51) $i s$

$$
B>\mu(1+\beta) .
$$

Proof. Suppose an economy with factor remunerations given by the exogenous distributional rule $\phi$ of expression (44) and constant positive growth. Let us also assume that rich and poor coexist in the long run. Proposition 1 implies that in the long-run equilibrium of good $x$ market,

$$
B \geq \frac{\eta}{2+\beta(2+\gamma)}\left(\frac{w_{t}+b_{t}^{R}}{p_{t}}+\frac{\Pi_{t+1}}{p_{t} r_{t+1}}\right)(1+\beta)+(1-\eta) \frac{w_{t}}{p_{t}}
$$

\footnotetext{
${ }^{12}$ Notice that if $\phi=1$ we turn again to the case in which factor prices reflect marginal productivities. Then, as we analyzed in the previous section, the condition becomes $B \leq \mu$, making impossible to sustain an inequality equilibrium.
} 
By $w_{t} / p_{t}=\phi B$ and the existence of the rich,

$$
B>\eta \mu(1+\beta)+(1-\eta) \phi B
$$

Then,

$$
B>\frac{\eta \mu(1+\beta)}{1-(1-\eta) \phi}
$$

Notice also that

$$
\frac{\eta \mu(1+\beta)}{1-(1-\eta) \phi}<\mu(1+\beta)
$$

Therefore, if $B>\mu(1+\beta)$, (51) holds.

Inequality (51) is a feasibility constraint. It affirms that supply has to be higher than the sum of the minimal demand of the rich and the poor dynasties. This result raises one key question: Do changes in inequality affect feasibility?

To tackle this question, we focus our attention on the effects of changing the distributional parameter $\phi$ on the right-hand of inequality (51). The following Corollary shows that a higher participation of labor income in sector $X$ implies that it is more difficult to sustain both dynasties.

Corollary 1. Define

$$
\Psi(\phi)=\frac{\eta \mu(1+\beta)}{1-(1-\eta) \phi}
$$

Increasing $\phi$ reduces $\Psi(\phi)$, making more difficult to sustain both dynasties.

Proof. Follows directly from equation (53).

\section{Graphical analysis}

Figure 1 depicts Propositions 5 and 6, and Corollary 1. Proposition 5 shows that, for the existence of the poor, $B$ must be lower than or equal to $\mu / \phi$, which in the Figure is given by the upper black line. Proposition 6 proves that, if rich and poor exist, then $B$ must be higher than $\eta \mu / \Psi(\phi)$. In the Figure this bound is the lower black line. The gray shadow area exhibits the feasible $B$ depending on $\phi$, for which an inequality equilibrium is possible.

According to Figure 1, for low values of $\phi, B$ can be either high or low. Further, when $\phi$ increases, the feasible $B$ s get smaller. We interpret these results as follows. For 
extremely low values of $\phi$, wages are low, and increases in $B$ do not raise the demand of poor so high such that they can convert into rich people. Then, $B$ can be high, and rich dynasties can enjoy more of good $x$. By contrast, for larger $\phi$, wages can reach high levels when facing an increase in $B$, so production cannot be so high since poor people would be able to devote resources for leaving bequests.

Figure 1: Necessary Levels of $B$ when Rich and Poor Coexist

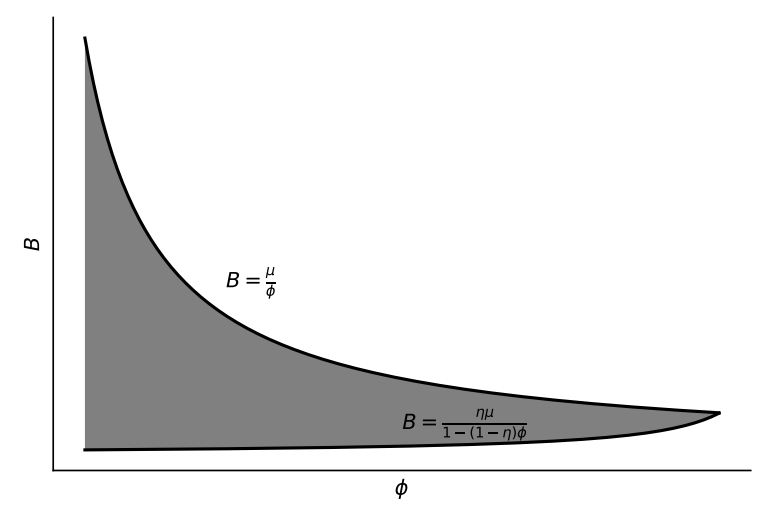

\section{How large can inequality get?}

In this part, we provide comparative statics about the effects of changing the bequest motive $\gamma$ and the share of labor income $\phi$. Specifically, we analyze the effects of these changes on income and wealth disitribution.

Let us define $\bar{s}$ as the long-term value of the savings-to-price ratio of the rich dinasty:

$$
\bar{s}=\frac{s_{t-1}^{R}}{p_{t}} .
$$

Since capital and wages grow at the same rate as the relative price, income and wealth distribution are stationary in the long run, but consumption inequality is increasing because rich experiment growing consumption of good $y$ and poor only consume a constant quantity of good $x$. As shown in Appendix C, the long-run income share of rich people $s h_{I}^{R}$ is

$$
s h_{I}^{R}=\frac{\eta\left[B\left(1+\frac{\gamma(1-\phi)}{2+\gamma}\right)+\bar{s} A\left(\frac{\gamma}{2+\gamma}+1\right)\right]}{\eta\left[B\left(1+\frac{\gamma(1-\phi)}{2+\gamma}\right)+\bar{s} A\left(\frac{\gamma}{2+\gamma}+1\right)\right]+(1-\eta)\left[\phi B\left(1+\frac{A}{1+g_{K}} \frac{\beta}{1+\beta}\right)\right]} .
$$


Similarly, the long-run wealth share going to rich people $s h_{W}^{R}$ is

$$
s h_{W}^{R}=\frac{\eta \bar{s}}{\eta \bar{s}+\frac{1-\eta}{1+g_{K}} \phi B \frac{\beta}{1+\beta}} .
$$

From 55 and (56) it follows that, ceteris paribus, (i) increasing $\bar{s}$ increases $s h_{I}^{R}$ and $s h_{w}^{R}$; (ii) increasing the bequest motive $\gamma$ increases $s h_{I}^{R}$; (iii) increasing $\phi$ reduces $s h_{W}^{R}$; and (iv) increasing $\phi$ also reduces $s h_{I}^{R}$.

Nevertheless, both $\bar{s}$ and $g_{K}$ are endogenous and depend on all the parameters of the model. Since this model does not present an analytic solution for these two variables, we solve it numerically and analyze the effects of changing $\phi$ and $\gamma$ on $s h_{w}^{R}$ and $s h_{I}^{R}$. The process employed to conduct this solution is developed in Appendix $D$.

Figure 2 shows the shares $s h_{W}^{R}$ and $s h_{I}^{R}$ for different values of the parameters $\beta$ and $\eta$, and the effects of changes in $\phi$ and $\gamma$. Panel (a) shows the comparative statics of changing $\phi$, holding $A$ and $\gamma$ constants, whereas Panel (b) displays the effects of changing the bequest parameter $\gamma$, holding $A$ and $\phi$ constant. The other parameters are chosen in such a way that guarantees positive growth and that the two dynasties prevail in equilibrium 13

Figure 2: Long-Run Income Share and Wealth Share of Rich Dynasties

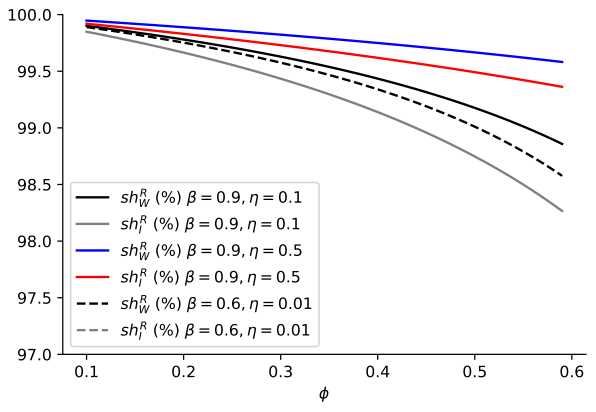

(a) Changes in $\phi$

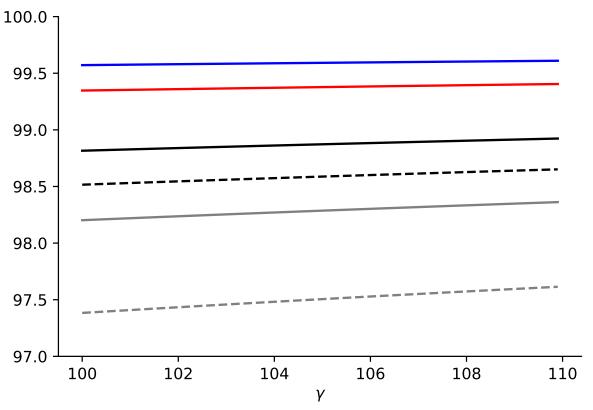

(b) Changes in $\gamma$

Long-run solutions of $s h_{I}^{R}$ and $s h_{W}^{R}$ for different values of the parameters $\beta$ and $\eta$. To compute these variables, $\bar{s}$ and $g_{K}$ are solved numerically with equations D.10 and D.12. Panel (a) shows the effects of changing $\phi$ with $\gamma=100$. Panel (b) shows the effects of changing $\gamma$, holding $\phi=0.6$.

Four main conclusions can be drawn from Figure 2. First, both income and wealth distribution are highly unequal. In all the cases exposed in the Figure, more than $90 \%$

\footnotetext{
${ }^{13}$ In particular, we select $\mu=1$ and $A=1.08$. For $\eta=0.1,0.01$, we employ $B=1$ and for $\eta=0.5, B=$
} 1.5 . 
of total wealth and income is on hands of the rich dynasties and this does not change for different values of $\phi$ and $\gamma$. Second, the inequality of wealth is higher than the inequality of income, a fact exposed by Piketty (2014). Third, inequality is increasing in the bequest parameter and decreasing in the exogenous rule $\phi$. Fourth, for higher values of $\eta, s h_{I}^{R}$ and $s h_{W}^{R}$ are higher than for intermediate and low values of $\eta{ }^{14}$

\section{Concluding Discussion}

We present an OLG model which considers the possibility of some agents not leaving bequests and the Pikettyian insights about that wages and interest rate are not determined by the law of marginal product. In our theoretical framework, once the agent can consume enough of the essential good, she initiates to leave bequests and consume the non-essential good. We characterize the possibility of the existence of two types of social groups: rich dynasties that save for the fortune of their heirs and poor dynasties that do not leave bequests and only save for their old age.

The behavior of the elasticity of substitution between capital and labor in the essential sector was key for the persistence of both dynasties in the long term. We are aware that the assumption of an elasticity lower than 1 in this sector could seem cherry picking. What this assumption is telling us is that, for the existence of a segmented society divided into rich and poor people, there must be as well segmented productive and consumption sectors. In a Marxist fashion, our analysis indicates that the production of the essential good has to be bounded, so that poor agents are restricted by the wage in terms of this good.

What kind of goods does exhibit these technological and price evolution patterns? One possibility might be housing. In fact, there is a lot of evidence indicating that the real house prices have risen since the second half of the 20th Century (Belfield et al., 2015; Albouy et al., 2016; Knoll et al., 2017; OECD, 2019) and that the share of expenditure devoted to this good has grown (Albouy et al., 2016). Another candidates are education and health care services, and there is as well evidence documenting that the prices of these goods have increased more than the consumer price index (McPherson et al., 1989; Archibald and Feldman, 2008; Baumol, 1993).

The issues of housing and services alone may generate enough discontent in the society and threat the normal functioning of a well-behaved market economy. Indeed,

\footnotetext{
${ }^{14}$ These figures are robust to different values of $\beta$ and $\eta$.
} 
the market process of housing and services are part of the drivers associated to the set of protest and riots in Chile that have generated surprise among economists and analysts, who see in this country an example of economic success in Latin America. According to the Chilean Family Budget Survey, after food, transportation is the second most important expense of families, followed by housing and basic services. In Chile, houses are expensive and this makes distant the dream of acquiring one. This is revealed by the "Housing Access Index" (PIR), released by the Chilean Chamber of Construction. The PIR indicates that an average household in Chile should allocate 7.6 years of its income to finance a property. Furthermore, the cost of buying a house or apartment has grown by almost $68 \%$ in eight years, while household income has grown $24.7 \%$.

\section{References}

Acemoglu, D. and Guerrieri, V. (2008). Capital deepening and nonbalanced economic growth. Journal of Political Economy, 116(3):467-498.

Albouy, D., Ehrlich, G., and Liu, Y. (2016). Housing demand, cost-of-living inequality, and the affordability crisis. Discussion Paper, University of Illinois.

Archibald, R. and Feldman, D. (2008). Explaining increases in higher education costs. The Journal of Higher Education, 79(3):268-295.

Barelli, P. and de Abreu, S. (2003). Inada conditions imply that production function must be asymptotically Cobb-Douglas. Economics Letters, 81(3):361-363.

Baumol, W. (1993). Health care, education and the cost disease: A looming crisis for public choice. Public Choice, 77:17-28.

Belfield, C., Chandler, D., and Joyce1, R. (2015). Housing: Trends in prices, costs and tenure. The Institute for Fiscal Studies, Election Briefing Note BN161.

Buera, F. and Kaboski, J. (2012). The rise of the service economy. American Economic Review, 102(6):2540-69.

Buera, F., Kaboski, J., and Rogerson, R. (2015). Skill biased structural change. NBER Working Paper No. 21165.

Buera, F., Kaboski, J., and Zhao, M. (2013). The rise of services: the role of skills, scale, and female labor supply. NBER Working Paper No. 19372. 
Ederer, S. and Rehm, M. (2018). Making sense of Piketty's 'fundamental laws' in a Post-Keynesian framework: The transitional dynamics of wealth inequality. Macroeconomic Policy Instutue Working Paper.

Foellmi, R. and Zweimüller, J. (2002). Structural change and the kaldor facts of economic growth. IZA Discussion Papers 472, Institute of Labor Economics (IZA).

Herrendorf, B., Rogerson, R., and Valentinyi, A. (2014). Growth and structural transformation. In Aghion, P. and Durlauf, S., editors, Handbook of Economic Growth, Vol. 2, pages 855-941. North-Holland.

Jones, C. (2015). Pareto and Piketty: The macroeconomics of top income and wealth inequality. Journal of Economic Perspectives, 29(1):29-46.

Kane, R. (1919). Directed structural change. Macroeconomic Dynamics, 23(5):19211958.

Knoll, K., Schularick, M., and Steger, T. (2017). No price like home: Global house prices, 1870-2012. American Economic Review, 107(2):331-353.

Kongsamut, P., Rebelo, S., and Xie, D. (2001). Beyond balanced growth. The Review of Economic Studies, 68(4):869-882.

Krusell, P. and Smith, A. (2015). Is Piketty's "second law of capitalism" fundamental? Journal of Political Economy, 123(4):725-748.

Krüger, J. (2008). Productivity and structural change: A review of the literature. Journal of Economic Surveys, 22(2):330-363.

Mankiw, G. (2015). Yes, $r>g$. So what? American Economic Review, 105(5):43-47.

Matsuyama, K. (2002). The rise of mass consumption societies. Journal of Political Economy, 110(5):1035-1070.

Mattauch, L., Klenert, D., Stiglitz, J. E., and Edenhofer, O. (2018). Overcoming wealth inequality by capital taxes that finance public investment. NBER Working Paper 25126.

McPherson, M., Schapiro, M., and Winston, G. (1989). Recent trends in u.s. higher education costs and prices: The role of government funding. The American Economic Review, 79(2):253-257. 
Mihalyi, P. and Szelényi, I. (2017). Wealth and capital: a critique of Piketty's conceptualization of return on capital. Cambridge Journal of Economics, 41(4):1237-1247.

Moav, O. (2002). Income distribution and macroeconomics: the persistence of inequality in a convex technology framework. Economics Letters, 75:187-192.

OECD (2019). Under Pressure: The Squeezed Middle Class. OECD Publishing, Paris.

Piketty, T. (2014). Capital in the Twenty-First Century. The Belknap Press of Harvard University Press.

Potter, M. (2014). Capital in the Twenty-First Century: A critique of Thomas Piketty's political economy. Agenda: A Journal of Policy Analysis and Reform, 21(1):91-113.

Quadrini, V. and Rios-Rull, J. (2015). Inequality in macroeconomics. In Atkinson, A. and Bourguignon, F., editors, Handbook of Income Distrbution, pages 1229-1302. North-Holland.

Zuleta, H. (2015). Factor shares, inequality and capital flows. Southern Economic Journal, 82(2):647-667. 


\section{A Consumer Problem}

\section{A.1 Interior Solution with $c x_{t}>\mu$}

In this case the first-order conditions imply:

$$
\begin{aligned}
p_{t} c x_{t} & =c y_{t}, \\
p_{t+1} d x_{t+1} & =d y_{t+1}, \\
\frac{d x_{t+1}}{c x_{t}} & =\beta r_{t+1} \frac{p_{t}}{p_{t+1}}, \\
d y_{t+1} & =\beta r_{t+1} c y_{t}, \\
p_{t+1} d x_{t+1} & =\frac{b_{t+1}}{\gamma} .
\end{aligned}
$$

Combining equations A.1b and A.1e wet

$$
d x_{t+1} p_{t+1}=d y_{t+1}=\frac{1}{\gamma} b_{t+1}
$$

Replacing (A.2) into $2 \mathrm{~b}$ yields

$$
\begin{aligned}
d y_{t+1} & =\frac{r_{t+1} s_{t}+\Pi_{t+1}}{2+\gamma}, \\
b_{t+1} & =\gamma \frac{r_{t+1} s_{t}+\Pi_{t+1}}{2+\gamma}
\end{aligned}
$$

Combining equations A.1a), A.1c, (A.1d, and A.3 with (2a), we get the solutions

$$
\begin{aligned}
c x_{t} & =\frac{1}{2+\beta(2+\gamma)} \frac{Z_{t}}{p_{t}}, \\
c y_{t} & =\frac{1}{2+\beta(2+\gamma)} Z_{t}, \\
d x_{t+1} & =\frac{\beta r_{t+1}}{2+\beta(2+\gamma)} \frac{Z_{t}}{p_{t}} \frac{p_{t}}{p_{t+1}},
\end{aligned}
$$

and

$$
b_{t+1}=\frac{\gamma \beta r_{t+1}}{2+\beta(2+\gamma)} Z_{t}
$$


Equation A.5 implies that if

$$
\frac{Z_{t}}{p_{t}}>\mu(2+\beta(2+\gamma))
$$

then this interior solution is feasible.

\section{A.2 Interior Solution with $c x_{t}<\mu$}

In this case the utility from $c y_{t+1}, d y_{t+1}, b_{t+1}$ is zero. Then, $c y_{t+1}, d y_{t+1}, b_{t+1}=0$ and the first-order conditions only imply equation A.1c. This equation combined with the budget constraints (2a) and (2b) implies the following solutions:

$$
\begin{aligned}
c x_{t} & =\frac{1}{1+\beta} \frac{Z_{t}}{p_{t}} \\
d x_{t+1} & =\frac{\beta}{1+\beta} r_{t+1} \frac{Z_{t}}{p_{t}} \frac{p_{t}}{p_{t+1}}
\end{aligned}
$$

and

$$
c y_{t}, d y_{t+1}, b_{t+1}=0 \text {. }
$$

From expression A.10 it follows that a necessary condition for this solution is:

$$
\frac{Z_{t}}{p_{t}}<\mu(1+\beta)
$$

\section{A.3 Corner Solution with $c x_{t}=\mu$}

In this case the agent fixes $c x_{t}=\mu$ and the first-order conditions yield equations (A.1b), A.1e, and

$$
d x_{t+1} p_{t+1}=\beta r_{t+1} c y_{t+1} .
$$

Thus, equations (A.3) and (A.4) also hold. Combining expressions (A.3) with A.1b 
and (A.14), and replacing them into (2a), we get the solutions:

$$
\begin{aligned}
& c x_{t}=\mu \\
& c y_{t}=\frac{1}{1+\beta(2+\gamma)}\left(Z_{t}-p_{t} \mu\right) \\
& d x_{t+1}=\frac{\beta r_{t+1}}{1+\beta(2+\gamma)}\left(\frac{Z_{t}}{p_{t+1}}-\frac{p_{t}}{p_{t+1}} \mu\right) \\
& d y_{t+1}=\frac{\beta r_{t+1}}{1+\beta(2+\gamma)}\left(Z_{t}-p_{t} \mu\right), \\
& b_{t+1}=\frac{\gamma}{2+\gamma}\left(r_{t+1} s_{t}+\Pi_{t+1}\right)=\frac{\gamma \beta r_{t+1}}{1+\beta(2+\gamma)}\left(Z_{t}-p_{t} \mu\right) .
\end{aligned}
$$

From the last equations it follows that if

$$
\frac{Z_{t}}{p_{t}}>\mu
$$

then this solution is feasible.

\section{B Factor Demands and Market of Factors with an Exogenous Distributional Rule}

Expression 46 implies that economic profits in sector $X$ are

$$
\frac{\Pi_{t}^{X}}{p_{t}}=(1-\phi) G_{L_{X}}\left(K_{X_{t}}, L_{X_{t}}\right) L_{X_{t}}
$$

Therefore, total capital income is

$$
\frac{r_{t} K_{X_{t}}+\Pi_{t}^{X}}{p_{t}}=(1-\phi) X_{t}
$$

From factor mobility and equations $46 \mathrm{a})$ and $(46 \mathrm{~b})$, it follows that the relative price of $\operatorname{good} x, p_{t}$, is:

$$
p_{t}=F_{L_{Y}}\left(K_{Y_{t}}, L_{Y_{t}}\right) \frac{L_{X_{t}}}{\phi X_{t}}=\frac{F_{K_{Y}}\left(K_{Y_{t}}, L_{Y_{t}}\right)}{(1-\phi) G_{K_{X}}\left(K_{X_{t}}, L_{X_{t}}\right)} .
$$


Thus, in equilibrium we have the following relationship for the capital per worker in each sector:

$$
\left(\frac{B}{A}\right)^{\frac{\sigma_{Y}-1}{\sigma_{Y}}}\left(\frac{K_{Y_{t}}}{L_{Y_{t}}}\right)^{\frac{1}{\sigma_{Y}}}=\frac{\phi}{1-\phi}\left[\frac{K_{X_{t}}}{L_{X_{t}}}+\left(\frac{B}{A}\right)^{\frac{\sigma_{X}-1}{\sigma_{X}}}\left(\frac{K_{X_{t}}}{L_{X_{t}}}\right)^{\frac{1}{\sigma_{X}}}\right]
$$

According to this, as in the case of distribution given by marginal producitivities, (i) if $K_{Y}$ grows at a constant rate, capital in sector $X$ also grows; and (ii) growing prices comes together with rising capital.

\section{Distribution of Income and Wealth}

Total income $I$ in terms of good $y$ is the sum of rich people's and poor people's income:

$$
I_{t}=\eta\left(w_{t}+b_{t}+r_{t} s_{t-1}^{R}+\Pi_{t}\right)+(1-\eta)\left(w_{t}+r_{t} s_{t-1}^{P}\right)
$$

Dividing by $p_{t}$ the numerator and denominator, and using expressions (A.4), (47), and 25), the long-run income share of rich people $s h_{I}^{R}$ is:

$$
s h_{I}^{R}=\frac{\eta\left[B\left(1+\frac{\gamma(1-\phi)}{2+\gamma}\right)+\bar{s} A\left(\frac{\gamma}{2+\gamma}+1\right)\right]}{\eta\left[B\left(1+\frac{\gamma(1-\phi)}{2+\gamma}\right)+\bar{s} A\left(\frac{\gamma}{2+\gamma}+1\right)\right]+(1-\eta)\left[\phi B\left(1+\frac{A}{1+g_{k}} \frac{\beta}{1+\beta}\right)\right]},
$$

where $\bar{s}$ is the long-run ratio of the savings of rich to the price, i.e., $\bar{s}=\frac{s_{t-1}^{R}}{p_{t}}$.

According to equation (28), total capital is the sum of the savings of the preceding generations of rich and poor:

$$
K_{t}=\eta s_{t-1}^{R}+(1-\eta) s_{t-1}^{P}
$$

Therefore, dividing by $p_{t}$ the numerator and denominator, and using expression (25), the long-run wealth share of rich people $s h_{W}^{R}$ is

$$
s h_{W}^{R}=\frac{\eta \bar{s}}{\eta \bar{s}+\frac{1-\eta}{1+g_{K}} \phi B \frac{\beta}{1+\beta}} .
$$




\section{Long-Run Solutions of the Model}

In this Appendix we derive the system of equations employed to solve the two long-run endogenous variables of the model: $\bar{s}$ and $g_{K}$.

First, consider the equation for the growth rate of capital. According to expression (28), $\frac{S_{t}}{S_{t-1}}$ is equal to:

$$
\frac{S_{t}}{S_{t-1}}=\eta \frac{s_{t}^{R}}{S_{t-1}}+(1-\eta) \frac{s_{t}^{P}}{S_{t-1}} .
$$

Using equation 22 and $\mathrm{A} .4$, it follows that

$$
\frac{s_{t}^{R}}{S_{t-1}}=\frac{1}{2+\beta(2+\gamma)}\left[\frac{w_{t}}{p_{t}} \frac{p_{t}}{S_{t-1}} \beta(2+\gamma)+\beta \gamma\left(A \frac{s_{t-1}^{R}}{S_{t-1}}+\frac{\Pi_{t}}{S_{t-1}}\right)-2 \frac{\Pi_{t+1}}{A S_{t-1}}\right] .
$$

From equations (25) and 28,

$$
\begin{aligned}
\frac{p_{t}}{S_{t-1}} & =\frac{1}{\eta \bar{s}+\frac{1-\eta}{1+g_{K}} \phi B \frac{\beta}{1+\beta}}, \\
\frac{s_{t-1}^{R}}{S_{t-1}} & =\frac{\bar{s}}{\eta \bar{s}+\frac{1-\eta}{1+g_{K}} \phi B \frac{\beta}{1+\beta}} .
\end{aligned}
$$

Therefore, using (47) it follows that

$$
\frac{\Pi_{t}}{S_{t-1}}=\frac{\Pi_{t}}{p_{t}} \frac{p_{t}}{S_{t-1}}=\frac{(1-\phi) B}{\eta \bar{s}+\frac{1-\eta}{1+g_{K}} \phi B \frac{\beta}{1+\beta}}
$$

and

$$
\frac{\Pi_{t+1}}{A S_{t-1}}=\frac{\Pi_{t+1}}{A p_{t+1}} \frac{p_{t}\left(1+g_{K}\right)}{S_{t-1}}=\frac{B(1-\phi)}{A}\left(1+g_{K}\right) \frac{1}{\eta \bar{s}+\frac{1-\eta}{1+g_{K}} \phi B \frac{\beta}{1+\beta}}
$$

Combining the last expressions, we have that $\frac{s_{t}^{R}}{S_{t-1}}$ is equal to:

$$
\begin{array}{r}
\frac{s_{t}^{R}}{S_{t-1}}=\frac{\left(1+g_{K}\right)(1+\beta) \beta}{(1+\beta)\left(1+g_{K}\right) \eta \bar{s}+(1-\eta) \phi B \beta} \frac{1}{2+\beta(2+\gamma)}[\phi B(2+\gamma)+ \\
\left.\gamma(A \bar{s}+B(1-\phi))-\frac{2}{\beta} \frac{B(1-\phi)}{A}\left(1+g_{K}\right)\right]
\end{array}
$$


On the other hand, expression (25) yields

$$
\frac{s_{t}^{P}}{S_{t-1}}=\frac{s_{t}^{P}}{p_{t}} \frac{p_{t}}{S_{t-1}}=\frac{\left(1+g_{K}\right)(1+\beta)}{(1+\beta)\left(1+g_{K}\right) \eta \bar{s}+(1-\eta) \phi B \beta} \frac{\beta}{1+\beta} \phi B .
$$

Replacing equations (D.7) and (D.8) into (D.2), it follows that the growth rate of capital $g_{K}$ satisfies:

$$
\begin{array}{r}
\frac{S_{t}}{S_{t-1}}=1+g_{K}=\frac{\left(1+g_{K}\right)(1+\beta) \beta}{(1+\beta)\left(1+g_{K}\right) \eta \bar{s}+(1-\eta) \phi B \beta}\left\{\frac{\eta}{2+\beta(2+\gamma)}[\phi B(2+\gamma)+\right. \\
\left.\left.\gamma(A \bar{s}+B(1-\phi))-\frac{2}{\beta} \frac{B(1-\phi)}{A}\left(1+g_{K}\right)\right]+\frac{1-\eta}{1+\beta} \phi B\right\} .
\end{array}
$$

Therefore, in equilibrium $\bar{s}$ and $g_{K}$ must satisfy the following equation

$$
\begin{array}{r}
0=(1+\beta) \beta\left\{\frac { \eta } { 2 + \beta ( 2 + \gamma ) } \left[B\left(\phi(2+\gamma)+(1-\phi)\left(\gamma-\frac{2\left(1+g_{K}\right)}{\beta A}\right)\right)+\right.\right. \\
\left.\gamma A \bar{s}]+\frac{1-\eta}{1+\beta} \phi B\right\}-\left\{(1+\beta)\left(1+g_{K}\right) \eta \bar{s}+(1-\eta) \phi B \beta\right\} .
\end{array}
$$

Second, consider the equilibrium good $x$ market. In the long run, $B$ is equal to:

$$
\begin{array}{r}
B=\frac{\eta}{2+\beta(2+\gamma)}\left[\frac{w_{t}+b_{t}}{p_{t}}+\frac{\Pi_{t+1}}{p_{t} A}\right]+\frac{\eta \beta}{2+\beta(2+\gamma)}\left[\frac{w_{t-1}+b_{t-1}}{p_{t-1}} A+\frac{\Pi_{t}}{p_{t-1}}\right] \frac{1}{1+g_{K}}+ \\
\frac{1-\eta}{1+\beta} \frac{w_{t}}{p_{t}}+\frac{1-\eta}{1+\beta} \frac{w_{t-1}}{p_{t-1}} \frac{\beta A}{1+g_{K}} .
\end{array}
$$

Using equations (47), (A.4), and the long-term value of wage in terms of good $x$, the 
last expression implies that $\bar{s}$ and $g_{K}$ must satisfy the following equation:

$$
\begin{array}{r}
0=\left(1+g_{K}\right)^{2} \frac{\eta}{2+\beta(2+\gamma)} \frac{B(1-\phi)}{A}+\left(1+g_{K}\right)\left\{\frac { \eta } { 2 + \beta ( 2 + \gamma ) } \left[B \left(\phi+\frac{\gamma(1-\phi)}{2+\gamma}+\right.\right.\right. \\
\left.\left.(1-\phi) \beta)+\frac{\gamma}{2+\gamma} A \bar{s}\right]+\frac{1-\eta}{1+\beta} \phi B-B\right\}+\frac{\eta \beta A}{2+\beta(2+\gamma)}\left[B\left(\phi+\frac{\gamma(1-\phi)}{2+\gamma}\right)+\right. \\
\left.\frac{\gamma}{2+\gamma} A \bar{s}\right]+\frac{1-\eta}{1+\beta} \phi B \beta A .
\end{array}
$$

We employ expressions (D.10) and (D.12) to solve numerically $\bar{s}$ and $g_{K}$. 